\title{
A Linguistic Study of Borrowing in Moroccan Teenage Talk
}

\author{
Samira Elouakili (Corresponding author) \\ Ibn Tofail University, School of Humanities \\ Kenitra, Morocco \\ E-mail: samielouakili@yahoo.fr
}

Received: March 6, 2017 Accepted: March 27, 2017 Published: March 30, 2017

doi:10.5296/ire.v5i1.11022 URL: http://dx.doi.org/10.5296/ire.v5i1.11022

\begin{abstract}
This paper aims to examine one of the most productive linguistic resources Moroccan teenagers use widely to create novel lexical and phrasal items-borrowing. Of particular interest to us are the varied aspects of their borrowings' innovativeness, which has often been reported to be one of the main features of youngspeak. The examples are taken from recorded dyadic and triadic conversations mainly between six female high school mates and relaxed group interviews involving four of the latter and two female others from the same school. The results reveal first that Moroccan teenagers are 'linguistic doers' capable of creating, through borrowing, novel words and expressions to talk about their concerns, interests, and attitudes. Second, they corroborate findings of previous research that teenagers are highly innovative. To achieve innovativeness, they employ various linguistic and rhetorical devices and break the linguistic norms of both the source and recipient languages. The product is thus a distinct language that is colourful, vivid, and expressive, which scholars largely agree teenagers use to express their autonomy and affiliation to their peers.
\end{abstract}

Keywords: distinctiveness, humour, innovativeness, intensification, linguistic norms violation, people categorisation, youngspeak

\section{Introduction}

Teenagers' talk has recently been widely researched (Eckert, 2003; Martinez, 2011; Lopez, 2009; Zimmerman, 2009; Stenström, Anderson, \& Hasund, 2002), and has often been reported to be innovative. It has even been claimed to largely contribute to language change. Lopez, in a study of intensifiers in Madrid's teenage talk, for example, noticed that it presents a "breakdown of the conventional language" (p. 83), and Zimmerman concluded his review 
of the literature by observing that it is characterised by "a general anti-normative attitude" ( $p$. 123). It is not surprising then that Eckert ('Why Ethnography?') called them 'linguistic movers and shakers" (p. 1).

In Morocco, a linguistically diverse community where six main varieties-two mother tongues, Moroccan Arabic (MA) and Amazigh, Standard Arabic (SA), French, English, and Spanish, which are learnt at school- co-exist, academic research on the issue remains scarce; hence this paper aims to fill some of the gap focusing on Moroccan teenagers' borrowings. Our objective is first to examine the types of borrowing they use in daily interaction, and second explore some aspects of their innovativeness. The need to conduct this study is reinforced by the fact that we often hear adults, parents in particular, express deep concern about the highly stigmatized rude 'street language' their children bring home. Uncovering some aspects of youngspeak may, at least partially, help us understand how teenagers perceive themselves and others outside their group, and enable us to comprehend partially at least how language develops. First we provide a review of some relevant literature on the topic-mainly Haugen's (1950) widely adopted classification of borrowings in terms of loanwords, loan blends, and loan shifts, and Drange's (2009) study of anglicisms in Chilean and Norwegian adolescents' informal speech in terms of Halliday's (1978) functional approach. Then we describe the methodology we adopted, analyse the data, and finally attempt to account for it.

\section{Literature Review}

Borrowing is defined in the current paper as the incorporation or integration of any item, be it morphological, lexical, or phrasal, from one language, the donor language, into another, the host language. Also included in the definition are non-morphemic parts of words or splinters (Lehrer, 2007). The subject has been examined from different perspectives.

Some researchers were interested in setting criteria to distinguish between borrowed words and single word switches (see, for example, Sankoff, 2001). One of these is whether an item is part of monolinguals' speech or not: If it is, then it is classified as a case of borrowing; otherwise, it is not. Another is phonological and morphological adaptation. Borrowings (borrowed items) involve the latter. By contrast, single word switches retain their phonological and morphological structures. A further one is frequency of use. If a word is attested to occur in the speech of a large community of speakers, then it presents a case of borrowing. Otherwise, it is a single word switch. However, as Sankoff pointed out, these criteria are "unsatisfactory given the variability in the data" (p. 12). For example, it seems difficult to agree on how large a community using a given foreign word should be for the latter to be considered as a borrowed word.

Drange studied anglicisms in Chilean and Norwegian adolescents' informal speech in terms of Halliday's functional approach. She identified three functions in her data-the ideational or referential function, the interpersonal function, and the textual one.

As to the first function, anglicisms were found to "designate new inventions or habits" ( $\mathrm{p}$. 167). In other words, they were traditionally motivated for most words were nouns that "define the external world" (p. 169). More specifically, they were utilised to fill mainly 
technology-related lexical gaps in the teenagers' mother tongues, a fact that is also true of our borrowings in section 4.1

The second function is "related to how the speaker expresses his or her relation to the other participants in the conversation" (p. 169) and establishes and maintains relations with them. She observed that this function is important in her participants' language, and is used "notably to express prestige, to reinforce the message, to catch and maintain hearer attention, and so on, all of which are important for establishing and maintaining phatic communion among the adolescents" ( p. 171). In fact, she claimed that this is "a typical use in adolescent language" (p. 174) and can also be carried out through other types of expressive words such as vocatives and taboo words (see also Lopez, Stenström, Anderson, and Hasund, and Martinez). Actually, many of our borrowings fulfil the interpersonal expressive function, which reveals its significance in teen culture, as will be illustrated in sections 4.1 and 4.2.

Concerning the third function, which relates to creating variation in the text, synonymy and verbal games, mainly rhyme, were employed "to produce a double meaning, often with sexual undertones" ( $p, 174)$. In this regard, Spreckels (2009) reported that playful use of language is, in fact, a general preference among the young across different cultures, and further quoted Androutsopoulos: "An expressive and playful use of language has been claimed as a hallmark of adolescence, with regard to some lexical innovations" (p. 47). Examples from our data are also evidence of this tendency, as pointed to in section 4. 2.

Other scholars established typologies of lexical borrowing. For instance, Scotton (2002) distinguished between cultural and core borrowings. The former are items that denote concepts and objects which do not exist in the culture of the host language such as 'shura' in English, which is a loanword from the Arabic / fu:ra/ (the process of decision-making based on deliberation and consultation) and the English (and French) 'halalisation' (the process of making something halal) from the SA/halal/ (halal). The latter are borrowings which denote concepts the recipient language has corresponding native items for. For instance, /kafatira/ (kettle), which is used in northern Morocco, was borrowed from the Spanish 'cafeteria' (cafeteria) though MA has native alternatives for it such as /saxxan/ and /muqraz/.

Another typology, the most widely accepted of all perhaps (Sankoff), is Haugen's (1950). Haugen defined borrowing as "the attempted reproduction in one language of patterns previously found in another." (quoted in Hilts, 2003, p. 60), and used two criteria, 'importation' and 'substitution', to classify borrowings into loanwords, loan blends, and loan shifts, also known as calques or loan translations.

In Haugen's terms, loanwords, which is the simplest category, involve morphemic importation and no substitution (Appel \& Mysken, 1987, p. 165). In other words, free morphemes (since he spoke of loanswords) are imported from the source into the recipient language. They are usually phonologically and morphologically incorporated into the host language, and they may maintain their meaning or acquire a new one. A case in point is the Spanish 'almohada' (pillow), a loanword from the Arabic /almixadda/. Another is /kantina/ (bar/tavern) in the northern Moroccan dialect, which was borrowed from the Spanish 'cantena'. Whereas these words and 'shura' have kept their meaning, /kafatira/ has taken on a 
new one.

In loan blends or hybrid borrowings, both morphemic importation and substitution are involved since native items, be they free or bound morphemes, are combined with foreign ones to create new units of meaning. An example from SA is /la:-dimuqra:ti/ (non-democratic), from the SA/la:/ (not) and probably the French 'democratique'. Another is /sid lkamuni/ (Sid Lkamouni), another name for the Moroccan town Sidi Allal Elbahraoui, from the MA 'Sid' (a honorific title for a Sufi master, Allal Elbahraoui in the present case) and the French 'camp Moinier' (Moinier's camp), which, ironically, refers to the military headquarters set up by the French general-Moinier- in this town during the French colonisation of Morocco. 'halalisation' is a further example.

By contrast, loan shifts involve morphemic importation without substitution. They are simple or compound words created on an item by item translation of elements in the source language. The form then is native whereas the meaning is imported from the donor language. Frequently cited examples are compound nouns like the French 'gratte-ciel', which is based on the English 'skyscraper'. Another is the SA/Sulba sawda:?/ (black box), probably a calque of the French 'boite noire'.

Given the simplicity of Haugen's typology, for which it has seemingly been widely adopted, it is used below to classify the borrowings in our data. The loan blends category is broadened to include phrasal blends as well as loan blends consisting of splinters.

\section{Methodology}

The examples were extracted from two-hour dyadic and triadic conversations in MA involving mainly six girls aged between 19 and 20 who study at the same secondary school, Elmalqui School in Kebibat, Rabat, and who live in neighbouring areas-Kebibat and Akkariand two of their male school mates, who were passing by during the recording. Taking into consideration these two variables, the participants can be said to belong to the same average or very average socioeconomic background. The recording, in which our research assistant, one of the girls, used a smart phone, took place in natural contexts-the street, areas by the school building external walls, and the houses of two girls- in May and June 2015. Only when the recording had been completed were the participants informed about it and its purpose, and asked for their approval to use it, which they did not object to.

Given the limited examples the recording generated, we had to use data eliciting techniques. Four of the six girls who were accessible and two others of their female school mates belonging to the same socio-economic background were invited to the researcher's house in late July 2015, where they were requested to list in writing all the words and expressions they usually use with their female peers. To facilitate the task for them, seven topics, which, we had observed, recur in Moroccan youngspeak, were suggested: Appearance, personality, human relations, sex, drugs, money, and school. Nonetheless, the informants were encouraged and repeatedly reminded to cite any item they could think of and in any order, regardless of the suggested categories.

Upon the completion of the lists, we tried to have a 'chat over a cup of coffee and cakes' to 
have the items clarified, but we realised it was difficult to record six teenagers conversing about seven topics, most of which they looked enthusiastic about. They were then asked to return in twos or threes (the third being the assistant, who has a close relation with both the informants and the researcher) to explain and provide examples of contexts where a given item could be used. This could only happen in late August.

During the five-hour group interviews, many questions and items that had not previously been cited naturally emerged. Interestingly, the girls talked more with one another and even recalled events and stories in which a word or an expression was employed. Besides, items that had been listed in the first meeting came up in their 'talk', which provided a natural-like context. This was, in fact, confirmed by Schilling (2013) in her observation that "people being interviewed in peer groups would talk more with one another than with the interviewer and that the everyday interactional norms they have with their peer group members would supersede any artificiality introduced by the interview event or by the relatively standard speech of the interviewer" (P. 96).

We also tried to encourage the informants to talk and feel comfortable by occasionally sharing a few words used in our teenage. It was noticed, in fact, that they were more open in the second meeting; they even cited some taboo items they had refrained from using in the first session.

Besides, we have over two years observed teenagers talk and have had chats with them in five cities-Rabat, Sale, Kenitra, Larache, and Ksar-el-Kebir. In addition, last year, we supervised two seminars on youngspeak, one of which involved adolescents from one more city-Sidi Kacem. Considering all of these sources, we can say that the examples analysed in this paper, all of which occur in our participants' talk and lists, largely represent Moroccan teenage talk at least in these areas.

Most of the examples have been incorporated phonologically and morphologically into MA, and quite a few have adopted new meanings. We may then claim that they are well-established borrowings. The focus in our discussion is on the morphological and semantic levels; the phonological aspect is considered, though, when deemed crucial to the analysis. The examples were transcribed using the English letters except for the Arabic sounds for which English does not have close corresponding ones, in which case phonetic symbols were employed (see the appendix).

\section{Data Analysis}

A close look at the data reveals that Moroccan teenagers are heavy borrowers, which may be partly attributed to the fact that Morocco is, as stated earlier, a linguistically diverse situation, and partly to their being, like their peers, "fond of borrowing new items from other languages and even from other jargons" (Martinez, p. 106).

Borrowed items can, as mentioned above, be classified into three types-loanwords, loan blends, and loan shifts. The three categories are illustrated and analysed in the following. 


\subsection{Loanwords}

Most recurrent are loanwords probably due to the simple process they involve. Many are borrowed from French, Moroccans' second language, and a large portion of these pertains to technology-the internet, social media, and mobile phones. Below are examples from two conversations:

1. R : t-kunikt-i-ti lbarah ?

Did you get connected yesterday?

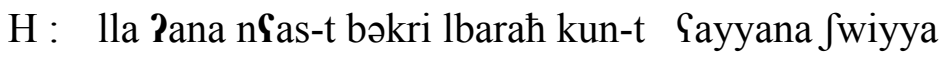

No. I went early to bed yesterday. I was a bit tired.

$\mathrm{R}$ : Pana Jat-i-t llil kaməl mৎa ddərriyat

I spent the whole night chatting with the girls.

2. S : fin sarha ?

What are you busy doing?

\section{F : kan-2a-zuț-i duk 33 uz Sandi}

I'm accepting those two's friend requests.

All the words in bold in these excerpts are French verbs that have been phonologically and morphologically incorporated into the verb system of MA. One point worth mentioning here is that the verbal form in the latter, and in Arabic in general, has a complex structure for it can stand for a whole sentence (Ennaji et al., 2004; Ryding, 2014). The reflexive French verb 'se connecter' in example (1) has turned into /t-kunikt-i-ti/ (Did you get connected ?), which is marked for the second person singular $\{\mathrm{you}\}$ and the past in the suffix $\{\mathrm{ti}\}$, and reflexivity in the prefix $\{\mathbf{t}\}$. Similarly, / $\mathbf{f a t}-\mathbf{i}-\mathbf{t} /$ (I chatted), the second complex verbal unit in the same example, is an adaptation of the French 'chatter' and carries the first person singular agreement and the past tense shown by the suffix $\{\mathrm{t}\}$. Likewise, /kan-Pazut-i/ (I'm accepting a friend's request) in (2) is marked for the present by $\{k a\}$ and the first person singular by $\{n\}$.

The data also features non-technology related loanwords of different grammatical categories - namely nouns and adjectives. Unlike verbs, the latter are not very complex in MA. They are generally inflected for number, gender, and definiteness; therefore, the adaptation process is much simpler. One recurrent set of nominal loanwords are names of school subjects related to science, as the following conversational extracts illustrate:

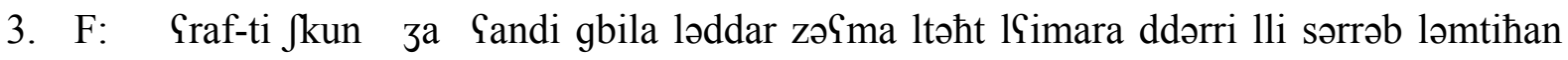
də-l-mat wəld yəイqub lmənșur

Do you kow who came to my house I mean the apartment building? The guy who leaked the math exam, the one from Yaàqub Lmansour.

M : huwwa lli sərrbu ? 
Is it him who leaked it?

\section{S: ta l-SVT tlah lyum}

The SVT exam has leaked today, too.

H : lla l-SVT dyal l-fizik dyal mmwalin l-PC

No, it's the SVT exam of the physics and chemistry students.

The French 'maths' (math) in (3), 'physique' (physics), and the acronyms SVT from 'science de la vie et de la terre' (the science of life and earth) and PC from 'physique et chimie' (physics and chemistry) in (4) have all been morphologically adapted: They all receive the definite article prefix $\{1\}$, in compliance with the MA rule according to which nouns are inflected for definiteness. The outcome is thus /lomtihan do-l-mat/ (the math exam), /ta I-SVT/ (the SVT (exam), too), and /dyal l-fizik dyal mmwalin l-PC/ (the physics exam of the physics and chemistry students).

In addition to the science-related loanwords, which tend to maintain their meaning, are recurrent nouns and adjectives denoting other semantic fields, many of which have taken on new meanings. The French 'soirée' (evening party) and 'moustache' (moustache) have both acquired the singular feminine suffix $\{a\}$ to generate the loanwords /swari-a/, which has retained its original semantic content, and /mustaf-a/, which refers to an extremely ugly girl, and sometimes one that resembles a man. The compound 'coup franc' (free kick) has been considerably modified to form the noun /kufr-a/, another well-established term for an extremely ugly girl. When used in the football field, where it first emerged, the loanword is /kufri/, which keeps its original meaning.

Concerning the adjectives, we cite /mə-stili/ and /mə-blisi/ from the respective French 'stylé' (stylish) and 'blessé' (hurt or wounded), and /mə-stuni/ from the English 'stoned'. As one can notice, the three adjectives are modelled on the same pattern $\{\mathrm{m} . . . \mathrm{i}\}$, which is usually used to generate the passive participle from weak triconsonantal verbs ending in /a/ in MA like /mə-bni/ (built) and /mə-nsi/ (forgotten) from the verbs /bna/ (build) and /nsa/ (forget), respectively (Ennaji et al., 2004, p. 37). Whereas the first adjective has maintained its meaning, the second and third have acquired novel ones. /mo-stuni/ refers to a person who is happy under the effect of drugs. /mə-blisi/ has a more specific derisive meaning: It denotes a scar-faced person who looks like a criminal.

From the analysis of the examples above, one can conclude that loanwords tend to be verbs, adjectives, and nouns, a fact well-attested in previous research conducted on different languages. "Major class content words such as nouns, verbs, and adjectives are the most likely to be borrowed" (Poplack and Machran quoted in Sankoff, 12 ; see also Appel and Mysken, 170-172, and Drange, 168). This can simply be attributed, as Appel and Mysken rightly claimed, to the fact that content word classes, unlike function words, "have a clear link to cultural content" (p. 171). We have also shown that they are morphologically integrated into the MA patterns, and that some of the non-science related category have taken on new meanings. 
One can further notice that Moroccan teenagers borrow for various reasons. Borrowings pertaining to technology and science in general can be said to be a natural consequence of the prevailing French vocabulary in this field, as Bentahila's study of language attitudes among Arabic French bilinguals in Morocco (1983) clearly demonstrated. Actually, French words such as the widely encountered 'installer' (install) have become an integral part of the French technological field whereas MA corresponding ones have not and are not expected to serve this function, since MA is the low variety in a situation that has variably been described as diaglossic (Bentahila), triglossic (Youssi, 1983), and quadriglossic (Ennaji, 2005), and is thus used in informal contexts. Its inappropriateness in this field was made explicit in one informant's account: "If I say / qbəltu/ (the MA word for 'accepted') for accepting a friend's request, it would not convey the technology-related concept". It is true that SA has developed its technological lexicon, but most teenagers are regularly exposed to the world of technology in French; hence the French technological lexicon is easier and faster to retrieve from memory. The same account can be said to hold for those denoting school subjects, all of which belong to the science field though they are taught in Arabic. By contrast, those related to human sciences such as Islamic education and philosophy are not borrowed.

As for the remaining loans, they are mainly used to categorise people in terms of their personal, physical, or social characteristics, an overwhelming tendency in teenage talk (Eckert, 2003; Spreckles). In fact, Moroccan teenagers' language abounds in lexical, phrasal, and even sentential units that classify people into different groups.

One more point worth mentioning is that some of the loanwords analysed above have close native synonyms, but the former are more economical and expressive./musta $\int \mathrm{a} /$, for instance, may refer to an extremely ugly girl or one who is extrmely ugly and resembles physically a

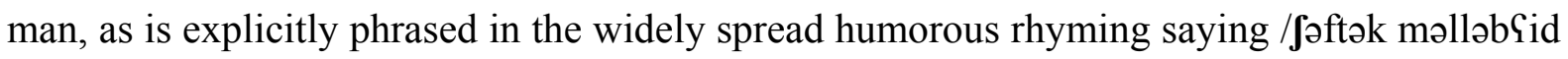
shabni şid Palmusțaja/ (I saw you form far away; I thought you were Siid, ugly girl). The use of 'Siid', a Moroccan traditional male name, intensifies the girl's ugliness. There is, to our knowledge, no MA word conveying the same meaning. /swaria/ is not the only item that has been created for a party. The native /zədha/ (hit / bang) also has been thought up. However, whereas the former refers to an evening party, the latter denotes a party where much loud music is played; neither has a synonym in MA.

Similarly, there exists no MA word for /məblisi/. To express the same idea-that one's face is full of scars, one can use a sentence such as /wuzhu kulu mfarrot// (literally, all his face is lined). Two close synonymous native creations to /məblis/ are the adjective /mxattot / and the noun /xuttututu/, but the scars here are on all or any part of the body. /məstuni/ does not have a native synonym, either. The closest ones are/morfuS/ (high in its drug sense) and /nafot/, which means either happy or happy under the effect of alcohol.

Thus these examples and others below clearly refute the claim that youngspeak is imprecise (Eckert, 'Adolescent language', p. 1), for Moroccan teenagers are capable of identifying lexical gaps in MA, discerning nuances of meaning, and eventually creating new items for concepts that seem important in their culture such as that of people categorisation. Some of these creations spread well beyond their sphere and acquire a larger number of users; they 
thus enter the lexicon of MA. A case in point is /blan/ from the French 'plan' (plan). This confirms findings of previous research in different contexts that teenagers are leaders in language change ( Eckert, 'Adolescent Language').

\subsection{Loan Blends}

Next in terms of frequency of occurrence are loan blends. Words, affixes, splinters, and phrases from MA, SA, French, and English are combined in a creative way to form novel words and phrases.

\section{$\underline{\text { Language combinations }}$}

MA/French

French/MA

SA/English

French/MA/English

MA/SA

\section{Examples}

5. /b-lo-bien/

6. /nifan-ment/

7. /impo-stahil/

8. /pro-Jkil/

9. /buku flus/

10. /les gens des bixxif/

11. /islam light/

12. /les hițis/

13. /Sniba min darazat Pamir ssuțh/

/b-lə-bien/ (literally, with well) in (5) and its native synonym /bə-1-məzian/, both of which occur as adverbs in excerpt (15) below, are structured on a pattern that is neither French nor Arabic. First, the French 'bien' as in 'Il a bien crié' (He shouted very much or very loudly) and its MA synonym /məzian/ (well/good) as in /dərba məzian/ (He beat her very much or very hard), by themselves, function as intensifying adverbs (as well as manner adverbs and adjectives). Second, $\{b\}$ or its variant $\{b ə\}$, the prefix preposition in MA, is usually added to nouns to form manner adverbs, and the French suffix \{ment\} is attached to adjectives to generate the same category. In the current examples, the bound MA morpheme is added to intensifying adverbs, both of which are widely encountered in the data. Using the conversational extract in (14), where H uttered emphatically /b-lo-bien/ and the (unusal in this context) exaggerated verb/txəwwər/ (utterly/severely messed up) to describe her sleep, we can claim that the unusual attachment 'doubly' intensifies the manner an action is performed.

14 M1 : malək dayra bhal fi sikkir

Why do you look like a drunkard?

H1 : maklit ttafiћummiṣa had șbah maklit tawəzza

I ate nothing this morning, nothing.

M2 : nti nSasti fəșbah ?

Did you sleep in the morning?

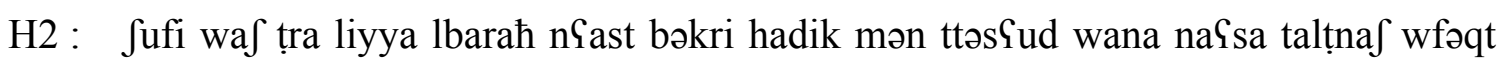
wbqit səhrana taldik 33uz Grəfti txəwwər liyya nnSas b-lə-bien 
You know what happened to me yesterday. I went to sleep early-at 9 and woke up at 12 and stayed up until 2 a.m. You know, my sleep got well messed-up.

Other evidence of this double intensification is provided in (15), where $\mathrm{N}$ uttered, in the same emphatic manner, the two adverbs when explaining the common hyperbolic SA/tamma qașu lqa:Sida binaza: $\hbar /$ (the base bombardment has been achieved successfully), which is used metaphorically to describe the successful teasing of a person and the resulting embarrassment it causes them. Intensification is also indicated in the repetition of the idea of teasing expressed in the new native creation / Jəqq/ (literally, slitting) using both the noun / Jəqqa/ and the verb /kay əəqqək/, and the latter's novel close synonym /kaynəwwət/, a loanword from the French 'note' (note).

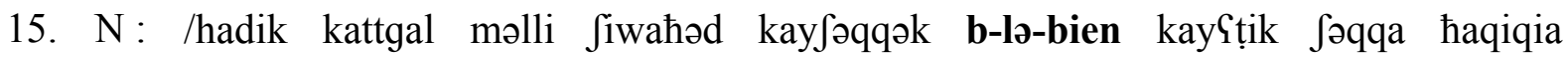
kaynəwwəț @lik bə-1-məzian/

(That is said when someone teases you hard, gives you a true teasing.)

The special use of intensification can finally be seen in the frequent use of another unusual exaggerated native creation-the geminated/mmut/ (death) in /mmut məzian/ and /mmut bi-xir/ (extremely well/good). The usual hyperbolic expression in MA is the non-geminated noun /mut/ followed by the preposition $\{\mathrm{d}\}$ or $\{$ dyal $\}$ and its object, as in /lmut dyal ḍ̣ahk/ (laugh to death).

The widely spread/nifan-ment/ in (6) is another example which violates both the MA and French morphological norms, for the MA adverb /nifan/ (seriously or honestly) receives the French suffix \{ment\}. The adverbial notion is expressed here again twice to amplify the honesty or seriousness of the manner an action is carried out. When requested for a clarification, the informants provided the synonymous emphatic Amazigh adverb / Payaras Payaras/, which Moroccans often use for the same purpose.

In fact, the use of unconventional intensification does not prevail only in our data, but has been found to be one of the main features of youngspeak in general. Martinez, for instance, observed British teenagers' "tendency to intensify language which also includes a characteristic use of some adjectives and adverbs" (p. 122; see also Lopez, p. 85 and Stenström et al, p. 139). It is also true that intensification and exaggeration, in particular, characterise humans' spontaneous speech in general and reveal their orientation towards dramatisation and amplification (Leech, 1983, p. 146 ; Claridge, 2011, p. 1), but they are predominant in youngspeak and characterised by novelty, which they achieve in the present cases through the violation of some morphological norms.

One last point to mention is that the pattern in (5) applies only to /məzian/, /bien/, and /xayəb/ (bad/badly) and that in (6) only to /nifan/ in our data, which may suggest that they are not productive. However, this is just apparent non-productivity for these words, which all function both as adjectives and adverbs, seem to be limited in number in MA.

Also recurrent in the data is the adjective /impo-stahil / (impossible) in (7), which combines the first splinter of the French adjective 'impossible' and the second of the SA adjective/mustahil/ (impossible) to produce a novel word denoting the same meaning. This 
creation is also unusual. First, unlike in blends such as 'brunch' and 'glocalisation' and loan blends such as the examples cited above, in which words or parts of words are usually joined to form items with new meanings, /impo-stahil / conveys the same meaning as that denoted by the separate words the splinters of which it is composed. Second, it does not exemplify a loan blend as defined by Haugen, for he spoke of morphemic importation whereas what constitutes the adjective here are two splinters, parts of words that do not form morphemes. It is still a case of blending as defined by Alegro (reported in Lehrer) : "Blends are underlying compounds which are composed of one word and part of another or parts of two (and occasionally three) other words" (p. 166).

Similarly, in /pro-jkil/ (problem) in (8), the first splinter of the French noun 'probleme' (problem) is combined with the second one of the Arabic /mufkil/ (problem) to generate again a nominal loan blend with the same meaning as that of the ones it is formed of. We witness then a violation of the same morphological norm as in (7).

One may perhaps account for the redundancy in (7) and (8) by relating it to adolescents' general tendency to play with words, as Drange's study (p. 174) reviewed above revealed. (See also Spreckels, p. 49). This, in fact, characterizes some native and borrowed items such as /tkunișța/from /tkunikța/ (get connected) and /kiksia/ from /siksia/ (sexy). However, one can notice that (7), (8), the common discontinuous blend /in-iqfis-able/ (difficult to understand), which is composed of the English (or French) affixes $\{\mathrm{in}\}$ and $\{$ able $\}$ and the MA noun /qfig/ (grasping), and the most recent native creation /muf-kbir/ (big problem) from /mufkil/ and / kbir/ (big), are all related to difficulty and problems. One may, therefore, suggest that difficulties, problems, and the impossible ruffle adolescents, who are often described as rebels, challengers of norms, and freedom seekers, and present significant challenges and obstacles in their life. Thus the redundancy mentioned above could be a linguistic reflection of the significant presence of problems and challenges adolescents have to meet, especially with adults.

In short, examples (5) to (8) show that Moroccan teenagers do not only create novel items but also model them on their own patterns challenging even the bound morpheme norms, which are among "the most resistant features of language-contact induced change" (Sankoff, p. 18). This violation also occurs at the syntactic level, as exemplified by (9).

The French quantifier 'beaucoup' (a lot) in (9) is combined with the MA noun /flus/ (money) to form the noun phrase (NP) /buku flus/, which often refers to a rich man. Alternatives to it are the creations /buku Saqa/, /buku ћəbba/, and /buku șərf/. In none of these phrases are the French and MA structural rules, which both require, after the quantifier, a preposition- 'de' and $\{\mathrm{dy}\} /\{\mathrm{d}\}$ respectively- abided by.

By contrast, the humorous /les gens des bixxif/ in (10) (literally, people of insects), which refers to a mob or the masses, is a NP modelled on the French nominal pattern: Article + Noun + Prepositional Phrase. It features the noun /bixxi $/$ /, which is a phonologically modified form of the MA/boxxuf/ (insects). This new shape might have been attributed to the native word for rhyming reasons. Semantically speaking, the nominal string is unusual for 'les gens' (people), do not belong to /bəxxu $/$. They are metaphorically the insects themselves whereas 
in French a NP built on the same structure such as 'les bras des filles' (the arms of the girls), the arms belong to the girls. However, the meaning remains clear. Besides, the phrase is humorous and may evoke in one's mind the vivid image of a noisy mob swarming down a street, for example, a group of noisy football team supporters trotting down the street after a match.

In brief, the phrase encompasses an unusual violation of selectional restriction rules, rhyme, metaphor, and humour, which, Goatly (2012) said, functions as "a control mechanism for enforcing norms within a group, including language norms", and plays a major role in "creating and reinforcing interpersonal relationships" (p. 131) such as rapport and intimacy. Combined together, these features give the expression vividness and colourfulness and, like (11), (12), and (13), (10) bears witness to Moroccan teenagers' "joy of explicit naming of social categories and the innovation of creative category labels" (Spreckels, p. 49).

/islam light/ (light Islam) in (11) shows Moroccan teenagers' interest in evaluating people in terms of another aspect of behaviour. It originally referred to a girl who wears a head-scarf but does not well cover the rest of her body, wearing, for instance, clinging or open collar garments, and was later broadened to describe a Moslem who dismisses some religious practices or performs some prohibited acts. Unlike/buku flus/, this phrase is in analogy to common collocations in SA such as / Pukla xafifa / (light meal) and /qahwa xafifa/ (weak coffee). In other words, it is subjected to the Arabic nominal structure, where the adjective follows the noun. We can then speak of syntactic adaptation (see also Stenström and Jørgensen, p. 3). Semantically speaking, 'light' is transferred from the field of food to that of religion, which is a new metaphor, and the expression is usually used sarcastically.

/les hițis/ in (12) is one more novel NP consisting of the French indefinite plural article 'les' and the new plural noun /hitis/, which is derived from the MA noun /hiț/ (wall). The phrase refers to cliques who 'play truant' and enjoy different forms of recreation or, to use another native creation-/ləSșir/, by the external walls of the school building-gossiping, playing, and telling stories and jokes. There is, to our knowledge, no MA item that conveys the same complex idea. (12) has then been created to fill a lexical gap, to name a concept that is highly significant in teen culture. It then fulfils an ideational or referential function, and thus falls within what is generally referred to as traditionally motivated borrowings, as mentioned in the second section.

However, there is nothing traditional about the phonological, morphological, and semantic structures of /les hitis/. First, both the noun and the article take $\{\mathrm{s}\}$, the plural marker, in compliance with the French rule, yet, unlike in French, the $\{s\}$ at the end of the noun is pronounced, in accordance with the plural pronunciation rule in English, with which most Moroccan secondary school students are familiar. Second, $\{\mathrm{s}\}$ is also assigned to the singular form of the noun. Third, the expression is structurally a French NP but the typically Arabic phonemes $/ \hbar /$ and $/ \mathrm{t} /$ are maintained. The phrase then mixes three languages, taking its syntactic and morphological patterns from French and its phonological structure from the three languages, a reflection of some of the linguistic diversity characterizing Morocco.

Of all the loan blends discussed in this section, /Sniba min darazat Pamir ssuṭh/ in (13) is, 
we think, the most humorous and creative social category label. It combines the MA diminutive noun / $\mathrm{nniba/}$ (small grape) and the SA prepositional phrase /min darazat Pamir ssuțh/ (of the rank of the prince of roofs). /Sniba/, an extremely derisive term extensively used to refer to an unmanly man who is continuously flirting with girls and trying all his best and at all costs to please them, is a highly productive word. It has generated, for instance, the

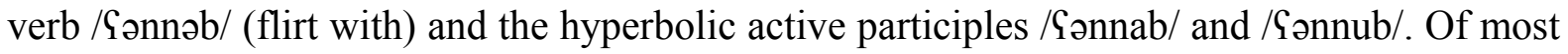
relevance to us is / Sniba min darazat ....../, where the slot can be filled with a name denoting the job of the flirter or a characteristic of his, as demonstrated by example (16) below.

For fear of missing the exact meaning of some words through translation, we content ourselves with the explanation of the content in (16). The latter was extracted from a conversation between two girls, $\mathrm{M}$ and $\mathrm{R}$. It started with a gossip about the divorce of a TV presenter, who is referred to as / Sniba/ in R1 and / Sniba min darazat muqaddim/ (a little grape of the rank of a TV presenter) in R3, and whose facial expressions on Women's Day are compared to those of a woman in M1 and M2. His wife is described as /mustafa/ (see section 4.1) in R1 and /ksida fəlhabța/ (an accident in the slope) in M1, both of which mean an extremely ugly girl in teenage talk. Then it shifted to another gossip about another/Sniba/, a /Sniba min darazat maitre nageur/ (a little grape of the rank of a swimming instructor) in M3. The latter had met $M$ at the beach and insisted on helping her swim, at which she laughed much (M4). 'Swimming instructor', it should be mentioned, is used sarcastically in this context for the flirter did not have that job. His trial at persuading $M$ to swim with him is but a flirting move she did not appreciate.

16. R1 : musțaja wəSniba

M1 : ksida fəlhabța huwwa aṣlan ktar mən Sənnab yaxti kaydir 1-karakṭir dləmra

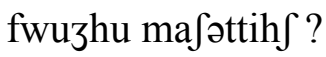

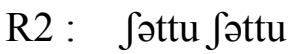

M2 : fYid lmarYa darha yadda șafi yatkun saliti ?

\section{R3 : Sniba min darazat muqaddim}

M3 : (laughs ) Sniba min darazat maitre nageur (laughing) Jhal ḍhakt Sliha dik lmərra

R4: $\quad$ Slaf? Jkun?

M4 : kant galtha liyya Amal Sniba min darazat maitre nageur Jhal ḍhakt katfufi yir nYawwmək nYawwmək

/Sniba min darazat Pamir ssutuh/ remains the most humorous of all. What is most striking and humorous about (13) is that a highly contemptuous word referring to a womanish man scorned by both men and women is assigned a rank in the SA phrase /min darazat ... .. / (of the rank of ....), which is usually followed by nouns denoting respectable positions, as in the military context. / $\mathrm{sniba/,}$ on whom effeminacy, lack of dignity, and authenticity are always imputed, is assigned the rank of a prince, to whom gallantry, attractiveness, and braveness are usually ascribed. The prince in (13), however, is not a charming one on a beautiful island or a 
brave heart throb in a dreamland but the prince of roofs, on which he unceasingly flirts with girls on the roofs of neighbouring houses or girls walking in streets. In this highly unexpected combination between very demeaning words and praising others, belonging to two varieties of opposing statuses-MA, the informal variety of the street and home, and SA, the prestigious formal language, lies the "incongruity mechanism" (Simpson and Mayr, 2010, p. 28), which is a crucial component in humour. (13) also involves an unconventional metaphor for the flirter is compared to a little grape, which one can easily crush and roll. It is further concise for it conveys a complex concept. Brief, (13) is highly expressive and innovative. Like the previously discussed examples, it clearly attests to Moroccan teenagers' skill to employ various resources innovatively to create lexical and phrasal items that allow them to talk about their life experiences and categorise people. In short, it bears evidence that they are creative 'linguistic doers'.

\subsection{Loan Shifts}

Unlike loanwords and loan blends, loan shifts, apparently like in MA, are barely present in our data. Only two cases were identified - /wəld lkəlba/ (son of a bitch) and /sa9a mətquba/ (literally, a hollow or pierced hour). The first is apparently a calque of the English 'son of a bitch'. The common synonymous phrase in MA is /wəld lqəћba/ (son of a whore) though /kəlba/ (bitch) may also be used to refer to a prostitute. This use, we think, is due to the popularity of English and English movies, in particular, among Moroccan teenagers.

The second example is a translation of the French 'heure creuse' denoting a one-hour lapse between two classes, during which /les hițis/ may practice their leisure activities or /ləS șir/ by the exterior walls of the school building. There exists no exact Moroccan item for the concept. The closest synonym is /saSa xawya/ (literally, empty hour), which means a free and not an in-between two classes free hour. It may be at the beginning or at the end of an afternoon, for example. /saSa məgfura/ (literally, a perforated hour) is another hyperbolic jocular expression for the same concept and further evidence of Moroccan adolescents' love for exaggeration.

In sum, Moroccan adolescents make special use of language and are deeply involved in the innovative creation of category labels, especially social ones (see also Elouakili, 2017). To account for this, we base ourselves mainly on the results of Eckert's ethnographic research in the public secondary school (2003 / 'Adolescent language'/ 'Why Ethnography?').

As the young, Eckert rightly argued, are moving away from childhood towards adulthood, they are deprived of work opportunities and placed in the secondary school. They are thus denied access to the world of economic and political power. Enclosed in the small institutional space that the school is, where they have to observe a considerable number of norms of and constraints on behaviour imposed by adults, adolescents are but expected to interact with their peers and seek to "make meaning of their existence and activities" (Eckert, 'Adolescent language', p. 2). This they attempt to achieve through the creation of an alternative world, where they oppose themselves both to adults and children and establish their own norms. This world is teen culture, where they try to "make a mark" (Eckert, 'Adolescent language', p. 2). (The emphasis is hers). 
The mark, Eckert further argued, materialises in various forms of cultural behaviour such as style in dressing, taste in music, and no less importantly linguistic behaviour. More precisely, the young's various behaviour patterns represent a rebellious reaction of a marginalised group against adults' "normative and power-laden" attitudes ('Why Ethnography?', p. 8). In Lopez' terms, they are "indicators of a kind of youth rebellion, of claims and demands" (p. 83), claims to a distinct identity and a distinct culture. We can further observe that the more resistance to and criticism of these behaviour patterns adults voice, the more insistent teenagers become in their attempt to preserve and emphasize their distinctiveness, for the latter is a loud claim to identity and an audible expression of the sense of belonging teenagers build and seek to maintain.

It should be mentioned, however, that adolescents do not construct their world and identity by opposing themselves to adults only, but also by creating "structure based on difference within the age group" itself (Eckert, 'Why ethnography?', p. 10). Zimmerman also spoke of "different forms of constructed identities of young people" (p. 120), whose linguistic behaviour may vary across sub-groups within the same school (Eckert, 2003, 'Adolescent Language'/“Why Ethnography?'). Eckert described the latter in different works as a "social hothouse", where teenagers from various backgrounds and of differing ideologies are confined. The confinement, adults' control, and the various developmental changes characteristic of this life stage make them compete for recognition and control of the social landscape. Hence, various groups emerge and try to exert different forms of social control; creating social category labels as well as others, as our data reveals, is one means they use to achieve this purpose (Eckert, 2003, p. 114). These categories, Eckert ('Adolescent Language') further noticed, "tend to be intense in their efforts to distinguish themselves from others through activity ranging from the elaboration of style to claiming territories to physical violence" (p. 5). It is only natural then that social and other category labels and intensification should prevail in Moroccan youngspeak.

\section{Conclusion}

To conclude, Moroccan youngspeak is characterised by a large presence of loanwords, a relatively important and interesting use of loan blends, and scarcity of loan shifts. This could be attributed, as stated earlier, to the simple process involved in borrowing single terms and the possibility of manipulating and 'juggling with' linguistic items that loan blends allow and which Moroccan teenagers seem to be fond of. As to the paucity of loan shifts, which seems to characterise MA in general, it could perhaps be due to the fact that it is easier and simpler to borrow items with their semantic content than to borrow meaning and find words or expressions for them in the source language, unless there exist none that could express the same semantic content. Further fieldwork, however, is required to confirm or refute this scarcity. The study also reveals high linguistic awareness capable of recognizing lexical gaps in MA and creating, through borrowing, novel items that convey concepts Moroccan teenagers seem to consider significant such as people categorisation and labelling. As a result, some of their creations, as mentioned before, are ratified by adults and integrated into MA (see also Eckert, 'Adolescent language'). 


\section{Al Macrothink}

International Research in Education

ISSN 2327-5499

2017, Vol. 5, No. 1

The study further shows that Moroccan adolescents are highly innovative. They deploy various morphological, semantic, syntactic, phonological, and rhetorical devices of both their mother and source languages, and violate the well-established norms governing them (see also Elouakili). The product is thus a distinct language characterised by humour, metaphor, intensification, preciseness, and expressiveness. On the one hand, this language expresses adolescents' distance from the parents' generation; on the other, it indicates their affiliation and loyalty to their peers (Stenström and Jørgensen, 2009, p. 2; see also Lopez, p. 93).

Further research could be conducted on Moroccan male teenagers' talk, and a comparison to the females' could be drawn to see how different or similar the two varieties are, which sub-group is more creative, and in what linguistic features and conversational behaviour. An exploration of adolescents' talk in public and private secondary schools may also reveal interesting results concerning the relation between their linguistic behaviour and socioeconomic background. In addition, an ethnographic study based in these schools may unravel different attitudes and orientations towards the school, society, and societal norms across peer groups, which we expect to be reflected in their language use. Finally a thorough exploration of the topics they talk about may enable the parental generation as well as educators and educationalists better understand their concerns and interests. This could, on the one hand, allow the designing of appropriate curricula and extra-curricular activities that are heedful of their needs and that can help them build their identity in a constructive way. On the other, it may enable the two generations bridge at least some of the gap between them.

\section{Acknowledgement}

All my sincere thanks are due to Prof. Boujemaà Boudali for proofreading this article. I am also deeply indebted to him for his support and encouragement.

I would also like to express my gratitude to my participants for their time and the rich data they provided me with.

\section{References}

Appel, R., \& Mysken, P. (1987). Language Contact and Bilingualism. Amesterdam: Amesterdam University Press.

Bentahila, A. (1983). Language Attitudes among Arabic/French Bilinguals in Morocco. England : Clevedon Company of Avon.

Claridge, C. (2011). Hyperbole in English - A Corpus-based Study of Exaggeration. New York: Cambridge University Press.

Drange, E. M. (2009). Anglicisms in the Informal Speech of Norwegian and Chilean Adolescents. In A. B. Stenström \& A. M. Jørgensen (Eds.), Youngspeak in a Multilingual Perspective. (pp. 161-175). https://benjamins.com. doi.org/10.1075/pbns.184

Eckert, P. "n.d". Why Ethnography?. 1-11. [Online] Available: https://web. Stanford.edu/ eckert.

Eckert, P. "n.d". Adolescent Language. 1-16. [Online] Available: https://web. Stanford.edu. 
/ eckert.

Eckert, P. (2003). Language and Adolescent Peer Groups. Journal of Language and Social Psychology, 22 (1), 112-118. [Online] Available: https://www.ffri.hr.

Elouakili, S. (2017). Derivation in Moroccan Teenage Talk. International Journal of Linguistics, 9(1), 26-41. http://dx. doi.org/10.5296/ijl.v9i1.10817

Ennaji, M. (2005). Multilingualism, Cultural Identity and Education in Morocco. www.springer.com.

Ennaji, M. Makhoukh, A. Es-saiydy, H. Moubtassim, M., \& Slaoui, S. (2004). A Grammar of Moroccan Arabic. Ben Abdellah University. Fes. Morocco. Retrieved from y.ennaji.free.fr

Goatly, A. (2012). Meaning and humour. Cambridge : Cambridge University Press.

Hilts, G. (2003). From Taxonomy to Typology : The features of Lexical Contact Phenomena in Atepec Zapotec-Spanish Linguistic Contact. 1-42. Retrieved from https://.linguistics.osu.edu

Lehrer, A. (2007). Blendalicious. In J. Munat (Ed.), Lexical creativity - Texts and Contexts (165-183). Amesterdam / Philadelphia: John Benjamins Publishing Company.

Leech, G. N. (1983). Principles of Pragmatics. New York: Longman.

Lopez, M. J. A. (2009). Lexical Innovations in Madrid's Teenage Talk - Some Intensifiers. In A. B. Stenström \& A. M. Jørgensen (Eds.), Youngspeak in a Multilingual Perspective. (pp. 81-93). https://benjamins.com. doi.org/10.1075/pbns.184

Martínez, P. I. M. (2011). The Language of British Teenagers - A Preliminary Study of its Main Grammatical Features. Atlantis. 33. 105-126. Retrieved from www.atlantisjournal.org

Ryding, K. C. (2014). Arabic : A Linguistic Introduction. Cambridge University Press. www.cambridge.org

Sankoff, G. (2001). Linguistic Outcomes of Language Contact. 1-27. Retrieved from www. ling.upenn. edu.

Schilling, N. (2013). Sociolinguistic Fieldwork. Cambridge University Press. www.cambridge.org. doi.org/10.1017/CBO9780511980541

Scotton, M. (2002). Contact Linguistics. Bilingual Encounters and Grammatical Outcomes. https://books.google.co.ma.

Simpson, P., \& Mayr, A. (2010). Language and Power. London / New York : Routledge.

Spreckels, J. (2009). Now he Thinks he's Listening to Rock music: Identity Construction among German Teenage Girls. In A. B. Stenström \& A. M. Jørgensen (Eds.), Youngspeak in a Multilingual Perspective. (pp. 1-53). https://dx.doi.org/10.1075/pbns.184

Stenström, A. B., Anderson, G., \& Hasund, I. K. (2002). Trends in Teenage Talk - Corpus Compilation, Analysis, and Findings. John Benjamins Publishing Company. http://dx.doi.org./10.1075/scl.8 


\section{Macrothink}

International Research in Education

ISSN 2327-5499

Stenström, A. B., \& Jørgensen, A. M. (2009). Introduction. In A. B. Stenström \& A. M. Jørgensen (Eds.), Youngspeak in a Multilingual Perspective. (pp. 1-9). https://dx.doi.org/10.1075/pbns.184

Youssi, A. (1983). La Triglossie dans la Typologie Linguistique. La linguistique, 12, 71-83.

Zimmerman, K. (2009). A theoretical Outline for Comparative Research on Youth Language with an Outline of Diatopic-contrast Research within the Hispanic World. https://dx.doi.org/10.1075/pbns.184

\section{Appendix: Key to the transcription symbols}

Vowels

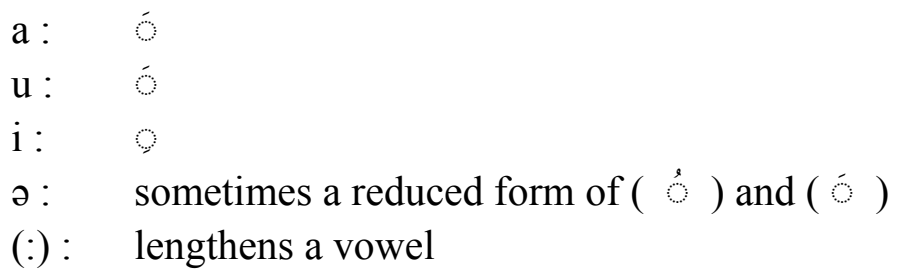

\section{Consonants}

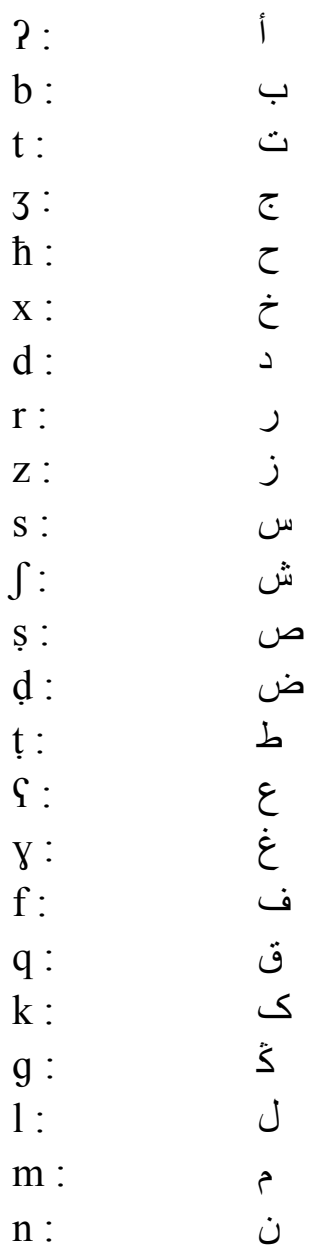




\section{Macrothink}

$\mathrm{h}$ :

$\$$

W: g

y: $\quad$ ي

\section{Copyright Disclaimer}

Copyright reserved by the authors.

This article is an open-access article distributed under the terms and conditions of the Creative Commons Attribution license (http://creativecommons.org/licenses/by/3.0/). 